\title{
Understanding teacher educators' beliefs and use of information and communication technologies in teacher training institute
}

\begin{abstract}
Technological competencies for teacher educators cannot be developed without consideration of an array of factors that impact the teaching and learning processes. This paper presents successful experiences and problems associated with the use of Information and Communication Technologies (ICT) as perceived by five teacher trainers. As realities indicate that there are significant barriers to the effective use of technology, the complex and less visible space of teacher trainers' must be addressed and understood. By understanding teacher trainers' beliefs and use, we can better design Continuous Professional Development (CPD) programmes plus other support system deemed necessary. Factors that both stimulate and obstruct will be discussed in this case study carried out in a Teacher Training Institute. Results among others highlight the need for technology environment that allows for learning and growth.
\end{abstract}

Keyword: Teacher educator; ICT; Focus group 